\title{
DEPÓSITO Y LECTURA DE UNA TESIS DOCTORAL: UNA ENCRUCIJADA DE TRÁMITES PROCEDIMIENTALES. UNA APROXIMACIÓN AL MARCO NORMATIVO DE LA UNIVERSIDAD DE MÁLAGA
}

\author{
DEPOSIT AND READING OF A DOCTORAL THESIS: A CROSSROADS OF \\ PROCEDIMIENTALES PROCEDURES. AN APPROXIMATION TO THE \\ NORMATIVE FRAMEWORK \\ OF THE UNIVERSITY OF MALAGA \\ ESTHER RANDO BURGOS \\ Doctora en Derecho \\ Profesora de Derecho Administrativo \\ erando@uma.es \\ Universidad de Málaga
}

\begin{abstract}
Resumen:
Desde el depósito provisional de una tesis doctoral hasta el día de la lectura y defensa ante el Tribunal, tiene lugar una etapa en la que queda aparcada la función investigadora para dar paso a la tarea del ciudadano que ha de dar debida cumplimentación al correspondiente procedimiento. Las nuevas bases fruto del relevante papel que se asigna al doctorado como intersección entre el Espacio Europeo de Educación Superior y el Espacio Europeo de Investigación, unido a la implementación de los procedimientos electrónicos, hacen adecuado un conjunto de reflexiones que constituyen el objeto de este trabajo.
\end{abstract}

Palabras clave: tesis doctoral, procedimiento, lectura y defensa, Universidad de Málaga.

\begin{abstract}
:
Since the provisional deposit of a doctoral thesis until the day of reading and defense before the Court, takes place a stage in which the investigative function is parked to give way to the task of the citizen who has to give due fulfillment to the corresponding procedure. The new bases fruit of the important role that is assigned to the doctorate as intersection between the European Space of Higher Education and the European Area of Investigation, together with the implementation of the electronic procedures, make appropriate a set of reflections that constitute the object of this work.
\end{abstract}

Keywords: doctoral thesis, procedure, reading and defense, University of Malaga.

Sumario: 1. Introducción. 2. El Doctorado: tercer ciclo de las enseñanzas universitarias. 3. La tesis doctoral. 4. Procedimiento para la lectura y defensa de la tesis doctoral en la Universidad de Málaga. 4.1. Autorización para la presentación formal y el depósito de la tesis. 4.2. Solicitud de admisión de la tesis doctoral: Propuesta de Tribunal y Propuesta de Evaluadores Externos. 4.3. Evaluación previa: Informes sobre la tesis.

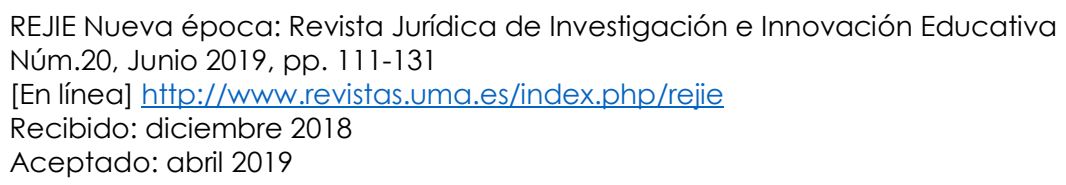


4.4. Depósito de la tesis doctoral y exposición pública. 4.5. Depósito electrónico: Registro en RIUMA y TESEO. 4.6. Lectura y defensa de la tesis doctoral. 5. Reflexiones. Bibliografía.

\section{Introducción.}

El feliz día en que, por fin, el doctorando, tras no pocos años de trabajo, una intensa labor investigadora e incluso importantes sacrificios en el ámbito profesional y personal, obtiene la conformidad de su director con la investigación realizada, llega el momento del depósito de la tesis doctoral con una meta de partida: su lectura y defensa ante el correspondiente Tribunal.

En ese momento, podría parecer que ha finalizado una compleja etapa que da paso a la preparación del acto de lectura y defensa, lo que, por lo general, tendrá lugar en un breve plazo de tiempo. Sin embargo, ese día en que se deposita la tesis doctoral, la aparente tranquilidad, indescriptible por otra parte, que supone haber concluido la etapa investigadora, rápidamente se desvanece cuando se toma consciencia del conjunto de trámites que se han de realizar para, en efecto, poder llevar a cabo la defensa ante el Tribunal.

Este período temporal, el que transcurre desde el propósito de llevar a cabo el depósito de la tesis doctoral hasta la lectura y defensa ante el Tribunal, es el objeto del presente trabajo y ello, no desde la perspectiva del investigador sino desde la del simple ciudadano que ha de cumplir preceptivamente con un conjunto de trámites que le posibiliten alcanzar el fin pretendido: obtener el título de Doctor. Y todo ello en un escenario que por lo general pinta complejo, al cansancio de años de investigación, intensificado en los últimos meses, se unen otros hasta entonces desconocidos, numerosos trámites, los diferentes plazos que se suceden y, en conjunto, la limitación temporal preestablecida para realizar el acto final así como las numerosas incertidumbres que surgen. Estos aspectos, desde una perspectiva práctica y desde la visión de quien recientemente se ha enfrentado a los mismos, son objeto de estudio en el presente trabajo.

En suma, el trabajo trata de abordar el procedimiento que conlleva la presentación formal de la tesis doctoral y el conjunto de trámites preceptivos hasta la lectura de la tesis doctoral, con la que finalizan los estudios de tercer ciclo. Todo ello conforme al Real Decreto 99/2011, de 28 de enero, por el que se regulan las enseñanzas oficiales de doctorado (en lo sucesivo, RD 99/2011) que establece un nuevo marco normativo en el que se desarrolla las previsiones relativas al tercer ciclo universitario contenido en la Ley Orgánica 6/2001, de 21 de diciembre, de Universidades, en la redacción dada por la Ley Orgánica 4/2007, de 12 de abril (en adelante, LOU). Desarrollo reglamentario que debe ser completado por las propias Universidades, en el ejercicio de su autonomía, a efectos de regular los aspectos concretos que la normativa estatal deja en sus manos. En este contexto, el trabajo toma como referente el desarrollado llevado a cabo por la Universidad de Málaga (UMA), plasmado en el Reglamento de los Estudios de Doctorado aprobado por el Consejo de Gobierno de la Universidad de Málaga de 9 de octubre de 2012 (para sucesivas menciones, Reglamento de Estudios de Doctorado de la UMA). 


\section{El Doctorado: tercer ciclo de las enseñanzas universitarias.}

Los estudios de Doctorado, tercer ciclo de las enseñanzas universitarias, tras los estudios de Grado y Máster, tienen por finalidad la especialización del estudiante en su formación investigadora dentro de un ámbito de conocimiento científico, técnico humanístico o artístico. Su concreción se encuentra en la LOU, cuyo art. 38 establece "Los estudios de doctorado, conducentes a la obtención del correspondiente título de carácter oficial y validez en todo el territorio nacional, que tienen como finalidad la especialización del estudiante en su formación investigadora dentro de un ámbito del conocimiento científico, técnico, humanístico o artístico, se organizarán y realizarán en la forma que determinen los estatutos, de acuerdo con los criterios que para la obtención del título de Doctor apruebe el Gobierno, previo informe del Consejo de Universidades. En todo caso, estos criterios incluirán la superación de un período de formación y la elaboración, presentación y aprobación de un trabajo original de investigación".

Su desarrollo se contiene, como se indicaba, en el RD 99/2011, regulación que, dentro de la construcción del Espacio Europeo de Educación Superior (EEES) ${ }^{1}$, tiene en cuenta las bases de la Agenda Revisada de Lisboa, así como la construcción del Espacio Europeo de Investigación (EEI) y los objetivos trazados en el Libro Verde de 2007, reconociendo al doctorado un papel fundamental como intersección entre ambos, en cuanto pilares fundamentales de la sociedad del conocimiento ${ }^{2}$.

\section{La tesis doctoral.}

El RD 99/2011 se refiere a la tesis doctoral como el trabajo de investigación original elaborado por el candidato en cualquier campo del conocimiento y que debe capacitar al doctorando para el trabajo autónomo en el ámbito de la $\mathrm{I}+\mathrm{D}+\mathrm{I}^{3}$.

Dicho trabajo de investigación es la culminación de una etapa en la que el doctorando, además de la elaboración de la tesis doctoral, habrá adquirido, a través del correspondiente Programa de Doctorado, las competencias ${ }^{4}$ y habilidades ${ }^{5}$ necesarias

\footnotetext{
${ }^{1}$ Sobre el nuevo marco diseñado por el Espacio Europeo de Educación Superior, vid. LIÑÁN GARCÍA, A. (2015) "El nuevo Espacio Europeo de Educación Superior: La puesta en valor del profesorado de las Universidades públicas españolas”. REIJE, Revista Jurídica de Investigación e Innovación Educativa. Núm. 12: págs. 23-32. Disponible http://www.eumed.net/rev/rejie/12/rejie12.pdf

${ }^{2}$ Sobre el nuevo marco europeo, vid. VALCÁRCEL CASES, M. (2009) "El posgrado en el marco del Espacio Europeo de Educación Superior: el caso español". La Cuestión Universitaria, Núm. 5 (Ejemplar dedicado a Europa pasa por Bolonia).

${ }^{3}$ Casi idéntico tenor emplea el Reglamento de Estudios de Doctorado de la UMA que define la tesis doctoral en el art. 18 como "La tesis doctoral consistirá en un trabajo original de investigación elaborado por el doctorando sobre una materia relacionada con el campo científico, técnico, humanístico o artístico del Programa de Doctorado realizado".

${ }^{4}$ El art. 5 del RD 99/2011, establece que los estudios de doctorado garantizarán, como mínimo, la adquisición por el doctorando de un conjunto de competencias descritas en el mismo, así como aquellas otras que figuren en el Marco Español de Cualificaciones para la Educación Superior.

5 Asimismo, la obtención del título de Doctor debe proporcionar una alta capacitación profesional en ámbitos diversos, especialmente en aquellos que requieren creatividad e innovación. Los doctores habrán adquirido, al menos, las siguientes capacidades y destrezas personales para:

- Desenvolverse en contextos en los que hay poca información específica.

- Encontrar las preguntas claves que hay que responder para resolver un problema complejo.

- Diseñar, crear, desarrollar y emprender proyectos novedosos e innovadores en su ámbito de conocimiento.

- Trabajar tanto en equipo como de manera autónoma en un contexto internacional o multidisciplinar.
} 
para la obtención del título de Doctor, mediante la realización del conjunto de actividades previstas en el mismo al objeto del desarrollo de los distintos aspectos formativos del doctorando y los procedimientos y líneas de investigación que posibiliten el desarrollo y realización de la tesis doctoral.

El RD 99/2011 establece un conjunto de principios generales, cuyo desarrollo y concreción corresponde a las diferentes Universidades, lo que obliga a acudir al marco regulatorio previsto por cada Universidad. En el caso de la Universidad de Málaga se contiene en el Reglamento de los Estudios de Doctorado aprobado por el Consejo de Gobierno de la Universidad de Málaga de 9 de octubre de $2012^{6}$.

El art. 13.2. párrafo segundo, del RD 99/2011 señala que las Universidades, a través de la Escuela de Doctorado o de la correspondiente unidad responsable del Programa de Doctorado, establecerán procedimientos de control con el fin de garantizar la calidad de las tesis doctorales, incidiendo especialmente en la calidad de la formación del doctorado y en la supervisión. El Reglamento de Estudios de Doctorado de la UMA, establece con dicha finalidad un conjunto de previsiones para dar debido cumplimiento a este mandato, diferenciando, como lo hace el precepto de referencia, entre los procedimientos de control durante la fase formación del doctorando y los destinados al control de calidad de la tesis doctoral. Entre los primeros, se establece el documento denominado Compromiso Documental de Supervisión ${ }^{7}$, el Documento de Actividades del Doctorando ${ }^{8}$ y el Plan de Investigación ${ }^{9}$.

- Integrar conocimientos, enfrentarse a la complejidad y formular juicios con información limitada.

- La crítica y defensa intelectual de soluciones.

${ }^{6}$ Con las modificaciones aprobadas en los Consejos de Gobierno de la Universidad de Málaga de 19 de julio de 2013, de 19 de junio de 2014, de 13 de mayo de 2051, de 27 de junio de 2016 y de 28 de junio de 2017.

Disponible https://www.uma.es/doctorado/info/22402/reglamento-doctorado/

${ }^{7}$ Definido por el art. 14 del Reglamento de Estudios de Doctorado de la UMA como el documento que establece las funciones de supervisión y seguimiento de los doctorandos. Este documento, que habrá de ser firmado por el doctorando, el tutor, el director o directores de tesis, el coordinador del Programa de Doctorado, el director de la Escuela a la que esté adscrito el Programa y el Presidente de la Comisión de Posgrado, debe contener, como mínimo, los siguientes aspectos: modalidad escogida para la realización de los estudios (tiempo completo o parcial); criterios de evaluación utilizados por la Comisión Académica para realizar el seguimiento anual, relativos a cada uno de los años de desarrollo de la tesis; aceptación del procedimiento de resolución de conflictos establecidos por la Universidad de Málaga; aspectos relativos a los derechos de propiedad intelectual o industrial que puedan generarse en el ámbito del Programa de Doctorado.

${ }^{8}$ Regulado en el art. 15 del Reglamento de Estudios de Doctorado de la UMA. Se trata del documento en el que se recoge el registro individualizado de control para cada alumno matriculado en un Programa de Doctorado conforme al art. 2.5 del RD 90/2011 y en el que se inscribirán todas las actividades de interés para el desarrollo del doctorando, así como los informes anuales que realicen el tutor, el director de tesis y las evaluaciones anuales de la Comisión Académica. Este documento será regularmente revisado tanto por el tutor como por el director de la tesis y evaluado por la Comisión Académica responsable del Programa de Doctorado.

${ }^{9}$ El Plan de Investigación, regulado en el art. 16 del Reglamento de Estudios de Doctorado de la UMA, es el documento que, antes de finalizar el primer año en el Programa de Doctorado, habrá de elaborar el doctorando y que debe contar con el aval del tutor y director de tesis así como el visto buena de la Comisión Académica del Programa. Como contenido mínimo, incluirá: objetivos que se pretenden alcanzar en el trabajo de investigación, metodología, medios necesarios y planificación temporal estimada para el desarrollo del trabajo. El Plan de Investigación debe ser aprobado por la Comisión Académica del Programa de Doctorado, tras lo cual se incorporará al Documento de Actividades del Doctorado.

Sobre el Plan de Investigación tomando como referente las Ciencias Jurídicas, vid. RUIZ RESA, J.D. (2016) "La formación en investigación: cómo preparar un Plan de Investigación para realizar una tesis 
Por su parte, el Reglamento de Estudios de Doctorado de la UMA, regula en su art. 19, los diferentes mecanismos dirigidos al control de calidad de las tesis doctorales. Con carácter general, se fija la exigencia de realización de aportaciones de calidad por el doctorando durante el proceso de elaboración de la tesis doctoral ${ }^{10}$ y se delega a la Comisión Académica de cada Programa de Doctorado ${ }^{11}$ la determinación de los criterios de calidad mínimos para que una tesis doctoral pueda iniciar el trámite de evaluación y defensa, criterios que habrán de ser propuestos para su aprobación a la Comisión de Posgrado ${ }^{12}$, oída en su caso la correspondiente Escuela de Doctorado ${ }^{13 / 14}$.

doctoral en ciencia jurídica”. REIJE, Revista Jurídica de Investigación e Innovación Educativa, Núm. 14, junio 2016: págs. 23-40. Disponible http://www.eumed.net/rev/rejie/14/rejie14.pdf

10 Aportaciones de calidad, directamente relacionadas con el trabajo de tesis y realizadas durante el proceso de elaboración de la misma, cuya puntuación total sea igual o superior a 1 punto según los criterios de la Agencia Nacional de Evaluación de la Calidad y Acreditación (ANECA) en la evaluación de los Programas de Doctorado con Mención hacia la Excelencia, debiendo ser evaluadas con, al menos, 0,5 puntos. Como requisitos específicos, se indican tres: su presentación, publicación o aceptación para publicación, muestra o reproducción con posterioridad a la fecha de matrícula del doctorando; que conste la Universidad de Málaga, a través de la afiliación del director y/o del doctorando; el doctorando debe constar como primer o segundo autor.

11 Tanto Programa de Doctorado como Comisión Académica de Programa de Doctorado, son definidos en el art. 2, aptdos, 2 y 3, respectivamente, del Reglamento de Estudios de Doctorado de la UMA. De esta forma, mientras el Programa de Doctorado es el conjunto de actividades conducentes a la adquisición de las competencias y habilidades necesarias para la obtención del título de Doctor que incluirá la organización y desarrollo de los distintos aspectos formativos de los doctorandos, los procedimientos para la elaboración de las tesis doctorales y las líneas de investigación en las que se realizarán dichas tesis doctorales, en consonancia con las directrices y estrategias de la UMA en materia de Doctorado, la Comisión Académica de cada Programa de Doctorado es el órgano responsable de su definición, coordinación, actualización y aseguramiento de la calidad, así como del progreso de la investigación, de la formación y de la autorización de la presentación de tesis de cada doctorando del Programa.

12 Por su parte, la Comisión de Posgrado, es definida en el art. 2.3. del Reglamento de Estudios de Doctorado de la UMA, como el órgano de regulación, decisión y control de las actividades relacionadas con los estudios de Máster Universitario y Doctorando, por delegación del Consejo de Gobierno y bajo su supervisión, en los términos establecidos en la normativa vigente. Su composición, competencias y normas de funcionamiento están recogidas en el Reglamento de la Comisión de Posgrado de la UMA, aprobado en Consejo de Gobierno de 9 de octubre de 2012 y modificado el 25 de octubre de 2013. Disponible https://www.uma.es/cipd/info/41342/reglamento-comision-posgrado/

13 La oferta de la Universidad de Málaga en el curso 2018/2019 se compone de 22 Programas de Doctorados, de los cuales 16 son propios y 6 interuniversitarios. Pueden consultarse en https://www.uma.es/doctorado/info/107958/oferta-doctorado-2017-18/

14 La Escuela de Doctorado de la Universidad de Málaga (ED-UMA) es la instancia encargada de coordinar los Programas de Doctorado de la Universidad adscritos a ella, y de planificar la oferta de actividades transversales dirigidas a la formación y desarrollo de los doctorandos. Todos los Programas de Doctorado de la UMA deben estar adscritos a la Escuela de Doctorado. El art. 2 del Reglamento de Estudios de Doctorado de la UMA, al regular la estructura organizativa de posgrado, establece que el Centro Internacional de Posgrado y Escuela de Doctorado (CIPD) de la UMA es el órgano encargado de organizar y coordinar, dentro de su ámbito de gestión, la oferta y actividades conducentes a los títulos oficiales de Máster Universitario y Doctorado que se lleven a cabo en la UMA. En este marco, señala que dentro de la estrategia de formación doctoral de la UMA se prevé la creación de Escuelas de Doctorado, adscritas al CIPD. Propiamente, a las Escuelas de Doctorando se les encomienda la planificación de la oferta necesaria de actividades inherentes a la formación y desarrollo de los doctorandos inscritos en los Programas de Doctorado adscritos a ella. Se establece además, el impulso para la creación de, al menos, una Escuela de Doctorado en la UMA, cuya estructura, organización, funcionamientos y objetivos se regulará en el correspondiente Reglamento. Más información sobre la Escuela de Doctorado de la Universidad de Málaga en https://www.uma.es/ed-uma/ 
Esta segunda cuestión, se concreta en la práctica a través de los diferentes criterios de calidad mínimos que los correspondientes Programas de Doctorado establecen ${ }^{15}$.

En el plano sustantivo, la tesis doctoral ha de respetar un concreto formato que expresamente recoge el art. 30 del Reglamento de Estudios de Doctorado de la UMA. En relación a su estructura, en cuanto trabajo de investigación, con carácter general la tesis debe estar integrada, como mínimo, por una introducción al tema de estudio y un resumen del estado de la cuestión, los objetivos que se persiguen con la investigación, la metodología, la exposición de la investigación realizada, la discusión de los resultados obtenidos, las conclusiones y un último apartado dedicado a la bibliografía recogida en el documento. Además, podrá complementarse con anexos.

También se regula el formato que ha de contener la portada del ejemplar, tanto en su portada como en el lomo. En la portada deberá constar "tesis doctoral", el título, el autor, el director, el programa de doctorado, el Centro (Facultad, Escuela o Escuela de Doctorado), la Universidad y el año. Por su parte, en el lomo debe constar igualmente la referencia a "TESIS DOCTORAL" (en mayúscula), según el propio Reglamento, el nombre completo del doctorado y el año.

No se establece, sin embargo, un formato concreto para el documento, ni en lo referente a su extensión, tipografía, tamaño, interlineado, formato de notas al pie de página, anexos o márgenes concretos. Estas cuestiones suelen ser, por lo general, orientadas por los directores de tesis que son quienes mejor conocen en la práctica las estructuras y formatos más habitualmente empleados en su rama científica. Tampoco se exige, un determinado encuadernado, diseño o color ${ }^{16}$.

\footnotetext{
${ }^{15}$ A modo de ejemplo, el Programa de Doctorado en Ciencias Jurídicas y Sociales tiene publicados los "criterios de calidad de las publicaciones que deben avalar las tesis presentadas en el Programa de Doctorado en Ciencias Jurídicas y Sociales de la Universidad de Málaga”, aprobado por la Comisión Académica del Programa en sesión de 29 de octubre de 2015. Entre las condiciones específicas previstas para este Programa de Doctorado se establece que sólo se tendrán en cuenta artículos en revistas científicas o libros que cumplan con las orientaciones de ANECA y fija un baremo en el que distingue según se trate de artículos en revistas científicas (en cuyo caso, indica que sólo serán valorados artículos publicados en revistas extranjeras de difusión internacional o artículos publicados en revistas españolas con JCR o que estén referenciadas en el directorio "Difusión y Calidad Editorial de las Revistas Españolas de Humanidades y Ciencias Sociales y Jurídicas" (DICE). Para el caso de revistas extranjeras o las españolas con JCR o referencias en DICE e incluidas en alguna de sus bases de datos con las categorías (A) o (B), la puntuación será hasta 1 punto; por su parte, las revistas españolas referenciadas en DICE y que se encuentren incluidas en algunas de sus bases de datos con la categoría (C) o, alternativamente, cumplan al menos 30 criterios LATINDEX, serán puntuadas con hasta 0,5 puntos) y libros (cuyas puntuaciones máximas serán de hasta 1 punto para monografías y hasta 0,5 puntos para capítulos de libros).

16 No obstante, es cierto que cada rama científica suele emplear un color distintivo con una larga trayectoria histórica. En consonancia con lo anterior, no es infrecuente que el color de las "tapas" del documento de tesis doctoral se identifique con la propia de la titulación en la que se encuadra.

Sobre la realización de tesis doctorales así como la plasmación de técnicas, procedimientos e incluso propuestas para su realización, existen diferentes trabajos de referencia. Pueden verse en este sentido, CRIADO SÁNCHEZ, A.J. (2017) Como hacer una tesis doctoral con los planes de Bolonia. Fundación Formación y Desarrollo Urbanístico, 2a edición; ECO, H. (2014) Cómo se hace una tesis doctoral: técnicas y procedimientos de estudio, investigación y escritura. Vol. 7, Editorial Gedisa; CAMINO, J.R. (2014) Cómo escribir y publicar una tesis doctoral. Editorial Esic.
} 


\section{Procedimiento para la lectura y defensa de la tesis doctoral en la Universidad de Málaga.}

El procedimiento para la lectura y defensa de la tesis doctoral contiene un conjunto de singularidades que hacen necesario un análisis detallado de los diferentes trámites que lo conforman. Su concreta regulación compete a cada Universidad, en el marco de las previsiones contenidas en la LOU y el RD 99/2011. El propio art. 13.2. del RD 99/2011, en su primer párrafo, fija que serán las Universidades las que establezcan el procedimiento para la presentación de la tesis doctoral, incluyendo la determinación de un plazo máximo para la posterior lectura de la misma. En esta escueta regulación, únicamente se señala un presupuesto obligatorio: la necesidad de garantizar la publicidad de la tesis doctoral durante el proceso de evaluación y con carácter previo al acto de defensa al objeto de que otros doctores puedan remitir observaciones sobre su contenido.

Consecuencia de lo anterior, y al objeto de conocer el correspondiente procedimiento se debe acudir a la normativa propia dictada por cada Universidad. En el presente trabajo, se analiza el procedimiento establecido por la Universidad de Málaga contenido en el Reglamento de Estudios de Doctorado, en particular en los arts. 18 a $24^{17}$.

\footnotetext{
17 De similar forma, las diferentes Universidades cuentan con su propia normativa propia dictada en desarrollo del RD 99/2011. A fin de facilitar el acceso y posibilitar, en su caso, una perspectiva unificada en el ámbito autonómico de la regulación establecida, se recogen las siguientes:

Universidad de Almería: Normativa de Estudios Oficiales de Doctorado Universidad de Almería,

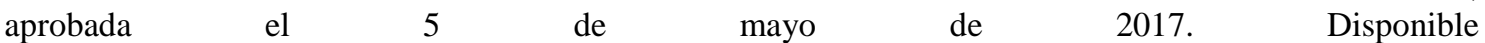
http://cms.ual.es/idc/groups/public/@centro/@eidual/documents/documento/normativaestudiosoficialesd octoradoeidua.pdf

Universidad de Cádiz: Reglamento de ordenación de los estudios de doctorado en la Universidad de Cádiz, aprobado por acuerdo del Consejo de Gobierno de 4 de mayo de 2016, por el que se aprueba la modificación del Reglamento UCA/CG06/2012, de 27 de junio de 2012, por el que se regula la ordenación de los estudios de doctorado en la Universidad de Cádiz. Disponible http://oficinadeposgrado.uca.es/wp-content/uploads/2017/10/17017.pdf?u

Universidad de Córdoba: Normativa reguladora de los Estudios de Doctorado, aprobada por Consejo de Gobierno de 21 de diciembre de 2011. Disponible https://www.uco.es/idep/doctorado/sites/default/files/archivos/documentos/normativa/NORMATIVA\%20 DOCTORADO\%202011.pdf

Universidad de Granada: Texto Refundido de las normas reguladoras de las enseñanzas oficiales de Doctorado y del título de Doctor por la Universidad de Granada, aprobada en Consejo de Gobierno de 2 de mayo de 2012 y modificada en Consejo de Gobierno de 30 de octubre de 2013. Disponible http://escuelaposgrado.ugr.es/doctorado/normativa

Universidad de Huelva: Reglamento de los Estudios de Doctorado de la Universidad de Huelva, aprobado en Consejo de Gobierno de 23 de abril de 2012. Disponible http://www.uhu.es/sec.general/Normativa/Texto_Normativa/Reglamento\%20Doctorado_Jul'14.pdf Universidad de Jaén: Reglamento de los Estudios de Doctorado. Disponible https://www.uja.es/departamentos/psicol/sites/departamento_psicol/files/uploads/reglamentodoctorado20 12_1.pdf

Universidad Pablo de Olavide: Normativa de Estudios Oficiales de Doctorado de la Universidad Pablo de Olavide, de Sevilla, aprobada en Consejo de Gobierno de 26 de noviembre de 2012. Disponible https://www.upo.es/postgrado/export/sites/default/PARTE_GENERAL/documentos_parte_general_docto rado_tres/Normativa-Doctorado_PARA-WEB_2015.pdf

Universidad de Sevilla: Acuerdo 9.1./CG 19-4-12. Normativa reguladora del régimen de tesis doctoral. Disponible http://www.doctorado.us.es/normativa/normativa-propia/nueva-normativa-reguladora-delregimen-de-tesis-doctoral
} 
Con carácter previo, cabe el interrogante de si nos encontramos propiamente ante un procedimiento administrativo. En este sentido, la única mención que contiene la Ley 39/2015, de 1 de octubre, de Procedimiento Administrativo Común de las Administraciones Públicas (LPAC), respecto a las Universidades se encuentra en su art. 2. El precepto regula su ámbito subjetivo de aplicación, y tras concretar en su aptdo. 1 su aplicación al sector público, integrado por la Administración General del Estado, las Administraciones de las Comunidades Autónomas y las Entidades que integran la Administración Local, precisa en el aptdo. 2, letra b), que las Universidades públicas, integradas en el sector institucional, se rigen por su normativa específica y supletoriamente por las previsiones de la LPAC. Similar previsión, contiene la Ley 40/2015, de 1 de octubre, de Régimen Jurídico del Sector Público (LRJSP), así, en su art. 2 integra al sector público institucional dentro de su ámbito de aplicación, precisando en su aptdo. 2, que el mismo queda integrado, entre otros, por las Universidades públicas que se regirán por su normativa específica y supletoriamente por la LRJSP.

Este aspecto, una de las principales novedades que aportan ambos cuerpos legislativos, resulta de entidad en la medida en que todo apunta a que las Universidades parecen quedar excluidas de la condición de Administración pública. Con independencia del acierto de tal medida ${ }^{18}$, lo cierto es que las Universidades se rigen por su normativa específica y, únicamente en los aspectos no contenidos en aquéllas, supletoriamente por la LPAC y la LRJSP. Consecuencia inmediata de los aspectos indicados es sí resulta adecuado hablar propiamente de procedimiento administrativo cuando nos referimos al conjunto de trámites preceptivos y que culminan con el acto de lectura y defensa de una tesis doctoral. A priori, todo hace indicar que, en sentido propio y sin perjuicio de los muchos matices que encierra, parece acertado hablar de procedimiento administrativo.

Ahora bien, identificado el procedimiento de defensa y lectura de la tesis doctoral como procedimiento administrativo, se plantea un segundo interrogante, en torno a si realmente nos encontramos ante un único procedimiento o ante dos procedimientos administrativos complementarios. Señalábamos con anterioridad, el procedimiento establecido en los arts. 18 a 24, en puridad referido al procedimiento de depósito de la tesis doctoral. Este procedimiento se inicia a instancia del doctorando mediante solicitud a la que habrá de incorporar una documentación concreta (relacionada en el art. 24) y únicamente para en el caso de superar con éxito el mismo, lo que tiene lugar con la autorización de defensa de la tesis doctoral (art. 25.1), tendrá lugar propiamente el procedimiento de defensa y lectura de la tesis doctoral cuya regulación se contiene en los arts. 25 a 29 del Reglamento de Estudios de Doctorados. Incluso la propia estructura del Reglamento, al distinguir en títulos separados estas cuestiones, incide en la idea anterior.

\footnotetext{
${ }^{18}$ Lo que no ha pasado desapercibido y ha dado lugar ya a diferentes trabajos que analizan la polémica generada. Pueden verse, entre otros, HUERGO LORA, A. (2016) "Las Leyes 39 y 40/2015. Su ámbito de aplicación y la regulación de los actos administrativos". El Cronista del Estado Social y Democrático de Derecho, $\mathrm{N}^{\circ}$ 63, IUSTEL, (ejemplar dedicado a: Las nuevas leyes de procedimiento administrativo común y régimen jurídico del sector público: págs. 4-13; AMOEDO SOUTO, C.A. (2017) "El impacto de las Leyes 39 y 40/2015 en las Universidades públicas: contenido, hipótesis y retos de futuro". Revista Española de Derecho Administrativo, $\mathrm{N}^{\circ} 182$ (enero-marzo): págs. 283-312; TARDÍO PATO, J.A. (2015) "¿Tiene sentido que las universidades públicas dejen de ser administraciones públicas en las nuevas leyes del sector público y de procedimiento administrativo común?. Documentación Administrativa: Nueva Época, $\quad \mathrm{N}^{\circ} 2 . \quad$ Disponible https://revistasonline.inap.es/index.php?journal=DA\&page=article\&op=view\&path\%5B $\% 5 \mathrm{D}=10267 \& p a$ th\%5B $\% 5 \mathrm{D}=10764$
} 
Siguiendo con el propósito del trabajo, en los siguientes apartados se detallan, según el orden a seguir, los diferentes trámites que tienen lugar desde el depósito de la tesis doctoral, sin obviar los requisitos previos para ello, hasta la obtención del título de Doctor, aportando la experiencia adquirida durante dicha etapa y tratando de aunar en este documento la diferente información, a veces dispersa, existente sobre el particular así como los formularios existentes.

A grandes rasgos, las fases que integran el procedimiento para la lectura y defensa de una tesis doctoral en la Universidad de Málaga (coincidentes con los que se seguirán para su análisis en los siguientes subapartados), son los siguientes:

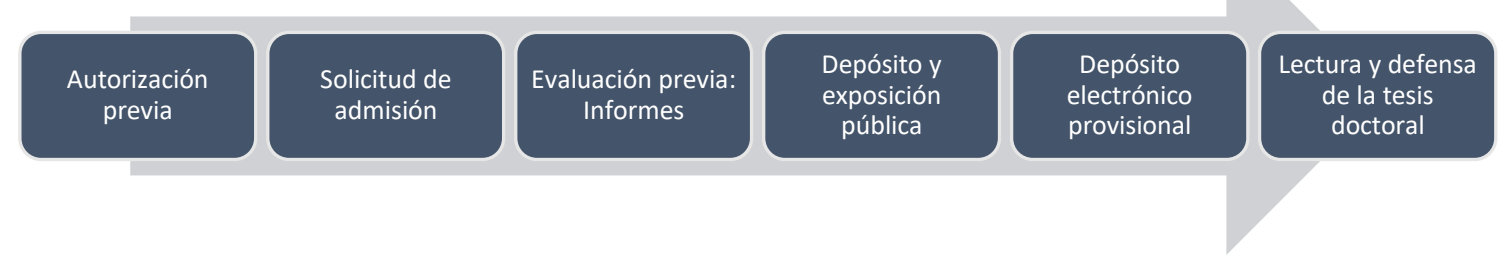

Esencial, con carácter previo al procedimiento en sentido propio, es hacer referencia a la "aplicación DAD"19 que, a modo de soporte, es el sistema implantado en la UMA y a través del cual se realizan la mayoría de trámites que en los sucesivos apartados serán analizados. En esencia, DAD, hace referencia al "Documento de Actividades del Doctorado" y surge para que los doctorandos puedan anotar a través del mismo todas sus actividades y cargar los diferentes documentos, aunque también para presentar solicitudes (cambios de dedicación, cambios de tutor o director, bajas temporales, etc). La aplicación también se encarga de gestionar el procedimiento de lectura y defensa de la tesis doctoral, simplificando y agilizando la tramitación del mismo. La aplicación cuenta con un manual en el que se explica su manejo ${ }^{20}$ y para su acceso se emplea la dirección de correo electrónica y clave DUMA (idéntica a la que se emplea para identificarse en la web de la UMA).

\subsection{Autorización de la Comisión Académica del Programa de Doctorado.}

Con carácter previo, para poder comenzar propiamente el procedimiento, cuyo inicio tiene lugar a instancia del interesado (doctorando), será preciso contar con determinados requisitos que habrán de acreditarse mediante su incorporación documental a la solicitud. En primer lugar, finalizada la elaboración de la tesis doctoral y obtenido el visto bueno del director, es necesario obtener la autorización de la Comisión Académica del Programa de Doctorado para su presentación y depósito. Para ello, ha de formularse una solicitud dirigida a la referida Comisión Académica que se acompañará, con carácter general, de la siguiente documentación ${ }^{21}$ :

- Dos ejemplares de la tesis, uno en soporte papel y otro en soporte electrónico.

- Currículum vitae del doctorando, en el que se especifiquen las actividades científicas realizadas en el período de investigación.

- Resumen de la tesis doctoral en formato electrónico.

- Relación de las contribuciones que avalan la tesis.

\footnotetext{
${ }^{19}$ Disponible http://dad.cv.uma.es/

${ }^{20}$ Disponible

https://www.uma.es/doctorado/navegador_de_ficheros/DocDoctorado/descargar/Manuales/Manual-DADv4.0.pdf

${ }^{21}$ Cuestión regulada en el art. 24 del Reglamento de Estudios de Doctorado de la UMA.
} 
- Autorización para la lectura del director y del tutor de la tesis, incluyendo un informe del director de la tesis donde se indique que las publicaciones que avalan la tesis no han sido utilizadas en tesis anteriores.

- Copia de los artículos, de los capítulos de libro, del libro o de los libros que avalan la tesis doctoral.

A estos documentos generales, se habrán de sumar otros que difieren según se trate de tesis por compendio o tesis con mención de Doctor Internacional. De esta forma, para el caso de solicitud de presentación de tesis por compendio, habrá de acompañarse el informe del director de la tesis donde se indique la idoneidad para la presentación de la tesis por compendio de publicaciones junto a la aceptación por escrito de los coautores de las publicaciones de que el doctorando las presenta como parte de la tesis y, en su caso, la renuncia de los coautores no doctores de dichos trabajos a presentarlos como parte de otras tesis doctorales. Para el caso de tesis que opten a la mención de Doctor Internacional, como documentación adicional habrá de presentarse la solicitud de mención de Doctor Internacional y la acreditación de la estancia ${ }^{22}$.

\subsection{Solicitud de admisión de la tesis doctoral: propuesta de Tribunal y propuesta de Evaluadores Externos.}

Autorizada la defensa de la tesis doctoral, conforme al art. 25 del Reglamento, la Comisión Académica del Programa de Doctorado, oído el director y, en su caso, el tutor de la tesis, formulará la propuesta del Tribunal que habrá de evaluar la tesis, tanto los miembros titulares como suplentes (tres en cada caso) así como a los evaluadores externos, acompañado de los méritos de los diferentes miembros.

En la práctica, la solicitud de admisión de la tesis doctoral, trámite que se realizará a través de la aplicación DAD, incluye los datos del doctorando (apellidos; nombre, DNI; correo electrónico; domicilio; C.P.; localidad; teléfono), los datos de la tesis doctoral (título; programa y centro responsable; director y tutor, con sus correspondientes correos electrónicos), la propuesta del Tribunal, distinguiéndose las funciones que desempeñará cada uno de los miembros (presidente, secretario y vocal, para el Tribunal titular; y el orden de suplencia para los miembros del Tribunal suplente) que serán relacionados en este orden e identificados (nombre, DNI, correo electrónico y Organismo al que está vinculado), así como la propuesta de los evaluadores externos, también identificados. A la solicitud habrá de adjuntarse el currículo de todos los miembros propuestos, tanto para formar parte del Tribunal como para evaluar la tesis, lo que tendrá lugar adjuntando dichos documentos a la aplicación DAD.

En relación con los miembros propuestos para conformar el Tribunal, serán seis, tres titulares y tres suplentes. Con carácter general, el Reglamento de Estudios de Doctorado de la UMA, exige que sean doctores, españoles o extranjeros, vinculados a Universidades u Organismos de enseñanza superior o de investigación y con

\footnotetext{
${ }^{22}$ Regulada en el propio art. 22 del Reglamento de Estudios de Doctorado. Se trata del documento en el que se acredite que durante el período de investigación el doctorando ha realizado una estancia mínima, no necesariamente continuada, de tres meses fuera de España en al menos una institución de enseñanza superior o centro de investigación de prestigio, cursando estudios o realizando trabajos de investigación bajo la responsabilidad de un doctor perteneciente a la institución extranjera. Extremos, tanto estancia como actividades, que deben ser avalados por el director de la tesis y autorizadas por la Comisión Académica mediante el correspondiente documento.

En la práctica este trámite y pese a su previsión expresa conforme a los términos expuestos en el Reglamento de Estudios de Doctorado, en la actualidad se realiza a través de la propia aplicación DAD sin que sea preciso, como anteriormente, obtener el documento físico.
} 
experiencia investigadora reciente acreditada. De los miembros titulares, sólo uno podrá pertenecer a la UMA, quien actuará preferentemente como presidente (función que se asigna al miembro que, perteneciendo a los cuerpos docentes universitarios, ostente el mayor rango académico) o secretario ${ }^{23}$. En el caso de los miembros titulares, sí que se exige que uno de ellos pertenezca a los cuerpos docentes de la $\mathrm{UMA}^{24}$. Todos los miembros deben acreditar mediante el correspondiente documento, denominado "Currículo de los Doctores propuestos como miembros de Tribunal de lectura de Tesis Doctoral en la Universidad de Málaga"25 (cuyo formulario también está previsto por la UMA), y como exige el art. 25.5 del Reglamento, tener experiencia investigadora en la temática de la tesis doctoral a evaluar ${ }^{26}$.

Por su parte, la solicitud también incluirá la propuesta de miembros de doctores evaluadores de la tesis, en un número de tres. El Reglamento de Estudios de Doctorado de la UMA, fija en su art. 26.1, los requisitos que deben cumplir dichos miembros. Los evaluadores propuestos serán doctores externos a la UMA, preferiblemente pertenecientes a instituciones de educación superior o institutos de investigación no españoles (no pudiendo coincidir con los miembros propuestos para actuar en el Tribunal de tesis, ni ser coautores de alguna de las contribuciones que avalan la tesis), con experiencia investigadora reciente acreditada, extremo que se acreditará mediante el correspondiente documento denominado "Currículo de los Doctores propuestos como evaluadores externos a la Universidad de Málaga" 27 que contendrá la justificación de los méritos de cada miembros relativos a los últimos cinco años, y que coincide con los datos que se solicitan para acreditar dichos extremos a los miembros del Tribunal.

Los diferentes documentos (solicitud de admisión de la tesis doctoral para su lectura y defensa junto a los currículos de cada miembro del Tribunal propuesto y de los evaluadores propuestos), una vez debidamente cumplimentados, serán incorporados a la aplicación DAD. Tras su comprobación por el Servicio de Doctorado, será elevado a la Comisión de Posgrado para su evaluación y la emisión de un informe en el que decide sí autoriza la admisión a trámite de la tesis con el Tribunal propuesto y designa a dos de los tres evaluadores propuestos ${ }^{28} \mathrm{o}$, bien, no autoriza su admisión a trámite con el Tribunal propuesto ni se designa a evaluadores externos, en cuyo caso habrá de motivar los motivos de tal decisión. También podrá requerirse al doctorando documentación adicional o cambios en su solicitud.

\footnotetext{
${ }^{23}$ Aunque el art. 25.3. del Reglamento de Estudios de Doctorado de la UMA, no exige que uno de los miembros del Tribunal titular pertenezca a la UMA, expresamente señala "podrá haber un miembro titular perteneciente a la Universidad de Málaga" (no así en los miembros del Tribunal suplente, de los que, al menos uno, sí debe pertenecer a la UMA), en la práctica, es recomendable que, al menos uno, de los miembros titulares del Tribunal pertenezca a la UMA.

${ }^{24} \mathrm{Si}$ la tesis opta a la Mención Internacional, al menos, uno de los miembros titulares y uno de los suplentes deberán pertenecer a una Universidad extranjera u Organismo de enseñanza superior o de investigación.

${ }^{25}$ Disponible en https://www.uma.es/doctorado/info/12385/formularios-doctorado/

${ }^{26}$ En la práctica, la acreditación de la experiencia investigadora, se lleva a cabo a través de los siguientes datos que habrán de incorporarse al citado formulario: participación en proyectos de investigación relacionados con el tema de la tesis (hasta 5 proyectos recientes); publicaciones relevantes relacionadas con el tema de la tesis (hasta 5 contribuciones recientes); tesis dirigidas sobre la materia (hasta 5 recientes); otros aspectos del currículo relacionados con la temática de la tesis.

${ }^{27}$ Disponible en https://www.uma.es/doctorado/info/12385/formularios-doctorado/

${ }^{28}$ De los tres evaluadores externos designados, la Comisión de Posgrado selecciona a dos. A modo de ejemplo, en nuestro caso fueron designados los dos primeros evaluadores propuestos en la solicitud.
} 


\subsection{Evaluación previa: Informes sobre la tesis.}

Si la admisión a trámite de la tesis es autorizada por la Comisión de Posgrado, dicho extremo se incorporará al expediente y a la aplicación DAD, siendo preciso a continuación la aceptación tanto de los miembros del Tribunal como de los evaluadores externos. Tras ello, a través de la propia aplicación se remite un correo tanto a los miembros del Tribunal como a los dos evaluadores externos designados, con un enlace para que puedan acceder a la documentación siguiente: ejemplar de la tesis doctoral, CV del doctorando, relación de la contribuciones que avalan la tesis doctoral y el modelo de informe de evaluación que habrán de cumplimentar y subir a la aplicación $\mathrm{DAD}^{29}$.

Este trámite ${ }^{30}$ es el que en la práctica puede demorar el procedimiento ya que los evaluadores externos disponen del plazo de un mes ${ }^{31}$ para la emisión del informe lo que resulta obligatorio. Junto a aquéllos, con carácter opcional, también podrán emitir informe los miembros del Tribunal de tesis, tanto los titulares como los suplentes, quienes serán invitados a ello y dispondrán de idéntico plazo. En caso de decidir no realizar el citado informe, deben expresamente indicarlo en este sentido, cuestión que también se ha de tener presente pues, en tanto no se pronuncien, continuará el cómputo del plazo hasta el transcurso del mes previsto para su emisión ${ }^{32}$.

Por su parte, los evaluadores externos, cuyo informe, como se indicaba, sí es preceptivo, tras la evaluación de la tesis doctoral se pronunciarán sobre la misma. De manera reglamentada, el art. 26.5. del Reglamento de Estudios de Doctorado de la UMA, con carácter general para los informes que se emitan tanto por los evaluadores externos como, en su caso, por los miembros del Tribunal, establece que los mismos incluirán una revisión pormenorizada de la tesis con los correspondientes comentarios y posibles sugerencias de mejora. En la práctica, la UMA cuenta con un documento normalizado denominado "Informe de Valoración de Tesis" así como un documento publicado por el Servicio de Doctorado y accesible a través de la web "Instrucciones Evaluadores Externos de Tesis" ${ }^{\prime 3}$.

\footnotetext{
${ }^{29}$ Aunque estas cuestiones no se pormenorizan en el Reglamento de Estudios de Doctorado de la UMA, se detalla en la página web del Servicio de Doctorado de la UMA. Disponible https://www.uma.es/doctorado/info/13421/tramite-admision-tesis/

30 Sobre la evaluación de la tesis doctoral, si bien no como trámite formal integrante del procedimiento cuya resolución posibilitará su lectura y defensa, sino también la evaluación posterior, tanto en el propio acto como a posteriori cuando la tesis opta al premio extraordinario de Doctorado e incluso cuando es publicada, vid. LÓPEZ YEPES, J., FERNÁNDEZ BAJÓN, M.T., SÁCHEZ VIGIL, L., MARTÍNEZ MONTALVO, E., HERNÁNDEZ PACHECHO, F., PRAT SEDEÑO, J., SÁNCHEZ, C.M. (2008) "Criterios para la evaluación de tesis doctorales". Revista General de Información y Documentación, Vol.18, No 1, págs. 293-322. Disponible http://revistas.ucm.es/index.php/RGID/article/view/10159

${ }^{31}$ Plazo previsto en el art. 26.2 del Reglamento de Estudios de Doctorado de la UMA.

32 Es por ello adecuado, al objeto de agilizar la tramitación, que, para el caso de decidirse por los miembros del Tribunal que no van a emitir informe previo de evaluación sobre la tesis doctoral, informen expresamente, a través del propio correo que les remite la aplicación DAD, sobre dicho extremo. De esta forma, emitidos por los miembros del Tribunal y por los evaluadores externos, se cumplimenta el trámite y puede continuar el procedimiento, incluso antes del mes previsto por la normativa.

${ }_{33}$ Disponibles ambos en https://www.uma.es/doctorado/info/81524/instrucciones-evaluadores-externostesis/

Los principales campos que incluye el informe de valoración de tesis son: título de la tesis; doctoral; datos de doctorando; datos de la persona que redacta el informe; resumen valoración (excelente, buena, suficiente o deficiente), apartado que recoge los siguientes aspectos (originalidad, metodología, relevancia de los resultados, discusión y conclusiones, bibliografía, presentación, publicaciones); recomendación (aceptar; cambios menores, cambios mayores, rechazar); informe justificativo de
} 
Uno de los aspectos más importantes de los informes de valoración de la tesis doctoral, son la "calificación" o "recomendación" que, sobre la misma, se realizan. En este sentido, el Reglamento de Estudios de Doctorado de la UMA, en el art. 26.5, habla de "calificación", en la que, de manera similar a la revisión utilizada en los procesos de revisión por pares de artículos científicos, el evaluador, señalará: aceptar, aceptar con cambios menores, aceptar con cambios mayores o rechazar.

La calificación depende en la práctica del tipo de comentarios que realice el evaluador y del tiempo que considere necesario para llevar a cabo los cambios sugeridos. De esta forma, el propio Reglamento concreta los criterios anteriores, fijando: cambios menores (menos de un mes); cambios mayores (menos de tres meses); rechazar (más de tres meses).

Recibidos los informes, la Comisión de Posgrado, a través de la aplicación DAD, los enviará al doctorando, al director y al tutor, con copia a la Comisión Académica del Programa de Doctorado. Es importante destacar que, aun en el caso de que alguno de los informes fuese negativo, mediante el rechazo a la defensa de la tesis doctoral, no es vinculante y ello conforme a la previsión del art. 26.9 del Reglamento de Estudios de Doctorado de la UMA que establece "En caso de que alguno de los informes sea negativo (Rechazar), el tutor y el director o directores de las tesis habrán de decidir por unanimidad si continúan o no con el proceso de defensa de la tesis. Si declinan continuar, el proceso se considerará concluido y será necesario comenzar de nuevo".

En síntesis, a la luz de los informes de evaluación, pueden tener lugar tres situaciones:

- Que se mantenga la tesis doctoral presentada.

- Que se modifique la tesis doctoral y se presente una nueva versión.

- Que se decline continuar con el procedimiento, retirando la tesis doctoral.

Para el caso de continuar con el procedimiento, lo que en la práctica es lo más probable pues no debe obviarse el trabajo que conlleva la elaboración de una tesis doctoral y el seguimiento continuo del director de la misma ${ }^{34} \mathrm{y}$, en su caso, el tutor, así como la previa autorización de éstos para poder comenzar el procedimiento que nos ocupa, pueden tener lugar dos situaciones lo que dependerá del sentido de los informes recibidos, del propio director y, en su caso, tutor de la tesis doctoral.

Aquí debe advertirse que aun en el caso de que los informes "acepten" la defensa de la tesis o, en otro caso, el director considere que pese a la sugerencia de "modificaciones menores/mayores" se mantiene el documento de tesis inicialmente presentado, ha de elaborarse un informe de "no cambios" sobre el manuscrito inicialmente depositado, el cual deberá incorporarse a la aplicación DAD para proseguir con el procedimiento. Si a la luz de los informes, el director decide realizar las modificaciones sugeridas, para las que se dispondrá de uno o tres meses, en función del carácter menor o mayor de las

valoración otorgada (puntos fuertes de la tesis y puntos débiles de la tesis); cambios sugeridos (cambios obligatorios y otros cambios propuestos); fecha; firma.

${ }^{34} \mathrm{Si}$ bien el presente artículo se centra en analizar la tramitación del procedimiento para poder llevar a cabo la defensa y lectura de una tesis doctoral, etapa formal y reglamentada, esencial para el éxito de una tesis doctoral es la figura del director, el "Maestro". En gran parte, de su labor dependerá no sólo el adecuado nivel de la tesis doctoral sino incluso poder llegar a este momento que representa la finalización de la tesis. Sobre esta cuestión vid. QUEVEDO-BLASCO, R. y BUELA-CASAL, G. (2013) "Evaluación de tesis doctorales: propuestas de mejora". Revista Mexicana de Psicología, enero, Vol. 30, Núm. 1: págs. 69-78. Disponible http://www.redalyc.org/html/2430/243033028008/ . Sobre el perfil de un buen director de tesis, vid. UBERTONE, F.P. (2011) "Elegir director de tesis· Academia. Revista sobre enseñanza del Derecho. Buenos Aires, Argentina. Año 9, Núm. 18: págs. 193-206. Disponible http://www.derecho.uba.ar/publicaciones/rev_academia/revistas/18/elegir-director-de-tesis.pdf 
mismas, podrá presentarse una nueva versión de la tesis que incorpore las modificaciones oportunas junto al correspondiente informe con el visto bueno del director sobre cómo ha resuelto los cambios sugeridos por los evaluadores en sus informes ${ }^{35}$.

\subsection{Depósito de la tesis doctoral y exposición pública.}

Cumplimentados los trámites anteriores, tendrá lugar la admisión a trámite de la tesis doctoral, lo que será comunicado a través de la propia aplicación DAD, y se informará de que a partir de dicho momento se puede solicitar la defensa de la tesis de doctoral.

La solicitud de defensa de la tesis doctoral conlleva como trámite previo por parte del doctorando, su formulación a través de la aplicación DAD para lo que deberá incorporar la versión definitiva de la tesis (aunque no se hayan producido cambios) y el informe sobre "cambios" o "no cambios" realizados sobre el documento inicialmente depositado.

Comprobado por el Servicio de Doctorado la correcta cumplimentación de la solicitud junto a la documentación necesaria, por parte del Secretario de la Comisión de Posgrado, será validada a través de la propia aplicación DAD. A partir del día siguiente de su validación, comenzará el cómputo de los quince días naturales de exposición pública de la tesis doctoral. Durante este período, la tesis quedará oficialmente depositada a efectos de que cualquier doctor pueda examinarla y, en su caso, remitir por escrito a la Comisión de Posgrado las consideraciones que estime oportuno formular. La publicidad de este trámite se realizará por el Programa de Doctorado así como por la Escuela de Doctorado a la que se encuentre adscrito el programa, a través de sus páginas webs, y en la que se informará de las tesis doctorales que en cada momento se encuentren en depósito, indicando el título, autor, director y Programa de Doctorado en el que se ha realizado.

Aunque no es frecuente que se realicen observaciones a las tesis en periodo de exposición pública, para el caso de tener lugar, el propio Reglamento de Estudios de Doctorado de la UMA, establece en su art. 27.5, que "En caso de recibirse observaciones a una tesis durante el periodo de exposición pública, serán comunicadas a la Comisión Académica del Programa de Doctorado, al director de la tesis y al doctorando, para que, a la vista de su contenido, manifiesten por escrito a la Comisión de Posgrado su opinión sobre la necesidad de continuar o paralizar el proceso, disponiendo para ello de un plazo de 7 días desde la finalización del período de depósito. En cualquiera de los casos, el doctorando podrá enviar un informe a la Comisión de Posgrado en donde responda a las observaciones realizadas sobre la tesis".

En este momento del procedimiento y, en tanto tiene lugar el transcurso del plazo de exposición pública de la tesis, es adecuado tener en cuenta otras cuestiones que serán precisas cumplimentar con carácter previo al acto de lectura y defensa, tales como el abono de los derechos de lectura, la cumplimentación de la ficha de TESEO $^{36}$ y el documento de conformidad del Servicio de Publicaciones de la UMA. A los dos últimos nos referiremos en el apartado siguiente. En relación con el documento de abono de los derechos de lectura, es el propio Servicio de Doctorado el que facilita el documento,

\footnotetext{
${ }^{35}$ Previsión contenida en el art. 26.10 del Reglamento de Estudios de Doctorado de la UMA.

${ }^{36}$ En el siguiente enlace se muestran un conjunto de recomendaciones del Servicio de Doctorado de la UMA relativas a la cumplimentación de la "ficha" en TESEO.

Disponible https://www.uma.es/doctorado/info/12632/recomendaciones?teseo/
} 
tras lo cual puede ser abonado en la correspondiente entidad bancaria y será devuelto a dicho Servicio para su incorporación al expediente.

Por su parte, la aplicación DAD envía un mail a los miembros del Tribunal, comunicándoles que tienen disponible la documentación definitiva depositada por el doctorado y a su disposición a través de dicha aplicación para su valoración y examen de cara a juzgar la tesis. En este momento del procedimiento la documentación que puede visualizar el Tribunal es la versión definitiva de la tesis doctoral, el CV del doctorando, la relación de contribuciones que avalan la tesis doctoral, los informes externos, el informe de respuesta del doctorando a los informes externos, el Documento de Actividades del doctorando así como, en su caso, las observaciones recibidas en el trámite de exposición pública así como los informes de respuesta del doctorando a cada uno de ellos.

\subsection{Depósito electrónico: Registro en RIUMA y TESEO.}

El art. 14.5 del RD 99/2011 establece que "una vez aprobada la tesis doctoral, la universidad se ocupará de su archivo en formato electrónico abierto en un repositorio institucional y remitirá, en formato electrónico, un ejemplar de la misma así como toda la información complementaria que fuera necesaria al Ministerio de Educación a los efectos oportunos".

Por su parte, el Reglamento de Estudios de Doctorado de la UMA, contempla esta cuestión en su art. 29 al referirse a la valoración de la tesis, cuyo aptdo. 9 señala "cuando la tesis doctoral haya obtenido la calificación de Aprobado, Notable o Sobresaliente, la Universidad de Málaga se ocupará de su archivo en formato electrónico abierto en un repositorio institucional y remitirá, a los efectos oportunos, un ejemplar de la misma al Ministerio de Educación en formato electrónico, así como toda la información complementaria que fuera necesaria".

En la práctica, la UMA tiene habilitado diversos mecanismos para dar cumplimiento a estos trámites pero es preciso aclarar que han de iniciarse antes del acto de defensa y lectura de la tesis doctoral, con independencia de que sea con posterioridad a este acto y una vez superado satisfactoriamente, cuando se culminen. De manera particular, dos documentos deben incorporarse al expediente que habrá de estar a disposición del Tribunal en el acto de lectura y defensa: Informe de depósito del Servicio de Publicaciones de la UMA y cumplimentación de la ficha TESEO.

En relación al primer trámite, el Informe de depósito del Servicio de Publicaciones de la UMA, con el que se da debido cumplimento a las previsiones normativas anteriores, se establece que todas las tesis defendidas en la UMA deben ser depositadas en formato electrónico en el Repositorio Institucional de la Universidad de Málaga (RIUMA) ${ }^{37}$. Será en el momento del depósito definitivo cuando, a través de la aplicación DAD, el doctorando reciba las instrucciones para el referido depósito con un enlace que posibilita acceder al formulario telemático. A través del mismo se harán constar los enlaces al archivo pdf que previamente se habrán subido a la consigna de la UMA.

El Servicio de Publicaciones y Divulgación Científica de la UMA tiene publicado en su web un documento síntesis en el que se concretan los pasos a seguir y a través del cual se pueden descargar los diferentes formularios ${ }^{38}$. Como cuestiones más relevantes del

\footnotetext{
${ }^{37}$ Disponible en https://riuma.uma.es/xmlui/

${ }^{38}$ Disponible en https://www.uma.es/servicio-publicaciones-y-divulgacion-cientifica/info/90542/publicatu-tesis/
} 
procedimiento para el depósito de la tesis en el repositorio de la UMA ${ }^{39}$ destacar que, recibida la solicitud de depósito, el Servicio de Publicaciones emite al doctorando un informe en el que señala que la tesis ha sido recibido y que reúne los requisitos para prepararla para su difusión pública. La emisión del referido informe queda condicionada a la remisión por parte del doctorando del "Acuerdo de edición y depósito de tesis doctoral en el Repositorio Institucional de la Universidad de Málaga (RIUMA)" 40. Obtenido el informe será presentado ante el Servicio de Doctorado para acreditar la cumplimentación del trámite de depósito electrónico de la tesis doctoral, documento que quedará incorporado al expediente.

Importante en este momento del procedimiento es tener en cuenta que, con carácter previo y para poder cumplimentarlo, se ha de solicitar el "Código ORCID"41. La propia Biblioteca de la UMA suele facilitar y ayudar en la cumplimentación de este trámite, para lo que es aconsejable contactar con el mismo.

El trámite de depósito electrónico en RIUMA presenta algunas particularidades según la modalidad de publicación que elija el doctorando. Si bien lo habitual es la publicación directa de la tesis en su formato original, puede tener lugar otras tres situaciones que dan lugar a algunas especialidades procedimentales: tesis por compendio de publicaciones $^{42}$, tesis realizada bajo acuerdo de confidencialidad ${ }^{43}$ o tesis conteniendo resultados pendientes de publicación ${ }^{44}$. En estos dos últimos casos, nos encontramos ante el conocido como "embargo de la tesis" y es muy importante tener en cuenta que

39 Procedimiento que se encuentra detallado en la en del Servicio de Publicaciones y Divulgación Científica de la UMA. Disponible http://www.spicum.uma.es/publica-tu-tesis.html

${ }^{40}$ Disponible en http://umaeditorial.uma.es/acuerdo_tesis_doctoral_solo_riuma.pdf

${ }^{41}$ El Código ORCID es un número identificativo que posibilita crear y mantener un registro único de investigadores que vincula las actividades de investigación y las publicaciones de los investigadores. Toda la información sobre el Código ORCID se encuentra disponible a través de su web. Disponible https://orcid.org/content/initiative?locale_v3=es

La Biblioteca de la Universidad de Málaga tiene recogida en su web toda la información relativa al Código ORCID y facilita la solicitud del citado identificador. Disponible en https://www.uma.es/ficha.php?id=135374

42 En cuyo caso debe subirse a la consigna de la UMA dos archivos pdf, uno en el que conste la copia literal de la tesis depositada en papel y otro en el que se sustituya la copia de dichos artículos por una página en la que conste su referencia (título, autores, revista en que fue publicado el trabajo, volumen, página inicial y final, año de publicación), el resumen de la publicación y su DOI (identificador único y permanente para las publicaciones electrónicas). Esta segunda copia es la que se publica en RIUMA y la primera es remitida al Ministerio de Educación.

43 En el supuesto de tesis derivadas de trabajos para los que existan firmados acuerdos de confidencialidad con empresas o instituciones, o exista la posibilidad de generación de patentes sobre el contenido de la tesis que impidan su difusión pública, habrán de subirse a la consigna de la UMA dos archivos pdf, uno con la copia literal de la tesis depositada en papel y otro consistente en un resumen de la tesis y de las conclusiones. La segunda copia es publicada en RIUMA y la primera es remitida al Ministerio de Educación.

${ }^{44}$ La tercera particularidad en el registro electrónico de tesis doctorales tiene lugar en aquellos casos en que esté previsto publicar inmediatamente la tesis después de su defensa. En este supuesto debe subirse a la consigna de la UMA la copia literal de la tesis junto con una autorización al "embargo" de la tesis, que impedirá que la tesis se haga pública en RIUMA hasta una año después de su lectura, plazo que podrá ser prorrogado por un año más si el doctorando lo solicita a la Comisión de Posgrado y así lo autoriza.

En referencia a la autorización señalada, que será precisa obtener no sólo para este último supuesto sino también para las tesis sobre las que existan acuerdos de confidencialidad firmados con empresas o instituciones, será preciso obtener la autorización de la Comision Académica del Programa de Doctorado y de la Comisión de Posgrado de la UMA para lo que se ha de solicitar ante el Vicerrectorado de Estudios de Posgrado, exponiendo las razones que concretas que justifican el embargo temporal de la tesis. La UMA tiene disponibles formularios previstos para la realización de este trámite. Disponible https://www.uma.es/doctorado/info/12729/tesis-repositorio-uma/ 
ha de solicitarse con anterioridad a la defensa de la tesis y en el momento en que se remite para su publicación electrónica a RIUMA.

Por otro lado, también será preciso cumplimentar la ficha en TESEO (base de datos de tesis doctorales del Ministerio de Educación) ${ }^{45}$. Como cuestiones de interés, tras el registro han de cumplimentarse los diferentes campos que incluyen, entre otros, datos del doctorando, datos sobre la tesis (título de la tesis doctoral, Universidad de procedencia, departamento, centro de lectura de la tesis, Programa de Doctorado), información sobre la tesis, dirección de la tesis y Tribunal. También es preciso tener en cuenta que habrá de adjuntarse un resumen de la tesis ${ }^{46}$.

Sobre este trámite es adecuado tener en cuenta tres cuestiones. En primer lugar, si se ha solicitado el embargo de la tesis doctoral, habrá de indicarse en la casilla correspondiente (en otro caso, podría ocurrir que, aunque se cuenta con el embargo por parte de la Universidad de procedencia y la tesis no será publicada en su totalidad hasta el cumplimiento de los plazos, podría publicarse en TESEO). En segundo lugar, aunque se cumplimente el trámite, es adecuado no finalizarlo hasta que tenga lugar la lectura de la tesis doctoral (la aplicación posibilita dejar el trámite en situación de "pendiente"), momento tras el cual se procederá a confirmar y "cerrar" la ficha ${ }^{47}$. Por último, una vez cumplimentada la ficha hay que generar el correspondiente documento e imprimirlo para su incorporación al expediente que habrá de tener el Tribunal el día de la defensa. Este documento habrá de ser firmado por los miembros del Tribunal e incorporado de nuevo al expediente para su tramitación por el Servicio de Doctorado.

\subsection{Lectura y defensa de la tesis doctoral.}

Cumplimentados debidamente los trámites precedentes, el acto de lectura y defensa tendrá lugar en un plazo máximo de tres meses desde la finalización del período de exposición pública ${ }^{48}$, siendo convocado por el Presidente del Tribunal quien acordará la fecha, lugar y hora en que tendrá lugar, previa consulta a los demás miembros. Dicho acuerdo, será notificado por el Secretario del Tribunal a la Comision de Posgrado de la UMA, con una antelación mínima de quince días naturales a su celebración. Realizado dicho trámite, la aplicación DAD genera un mensaje en el que comunica los extremos anteriores.

\footnotetext{
${ }^{45}$ Disponible en

https://www.educacion.gob.es/teseo/irGestionarConsulta.do;jsessionid=65F393FD7B56C887AFCAA710 DBA387F7

${ }^{46}$ En relación con el resumen que ha de incorporarse a la base de datos de TESEO, debe tener una extensión máxima de 500 palabras. En referencia a su contenido, el Ministerio de Educación (y así se encuentra también disponible en el Servicio de Doctorado de la UMA a través de su web) ha publicado la siguiente recomendación: "Un criterio que puede servir como pauta orientativa es entender el resumen igual que un comentario de texto, donde la presentación diferenciada de las partes, introducción o motivación de la tesis, desarrollo teórico, conclusión, y bibliografía consultada, cumpliría la condición de producir una base de datos eficaz y ofrecer en su consulta pública, una exposición ordenada y completa de los datos de la/del doctoranda/o, exponiendo la información de la tesis en formato "ficha"...".

Disponible https://www.uma.es/doctorado/info/12632/recomendaciones-teseo/

${ }^{47}$ Por ejemplo, podría darse la circunstancia de que alguno de los miembros titulares del Tribunal por circunstancias sobrevenidas no pueda comparecer y sea un miembro suplente el que finalmente conforme el Tribunal. Estas cuestiones deben recogerse en TESEO, lo que resultará más sencillo si el trámite se encuentra aún abierto pues únicamente se tratara de una modificación.

${ }^{48}$ Excepcionalmente y en circunstancias debidamente acreditadas, dicho plazo podrá ser ampliado por la Comision de Posgrado, posibilidad contemplada por el art. 28.1 del Reglamento de Estudios de Doctorado de la UMA.
} 
Por su parte, tanto la Escuela de Doctorado como el Centro al que se adscriba el Programa de Doctorado deben dar publicidad adecuada al acto de defensa de la tesis, anunciando con al menos siete días de antelación la fecha, lugar y hora de celebración del acto.

A efectos formales, el acto de defensa tendrá lugar en sesión pública y durante el periodo lectivo del calendario académico aprobado por la Comisión de Posgrado. A puerta cerrada, se constituirá previamente el Tribunal con la presencia de los tres miembros ${ }^{49}$, tras lo tendrá lugar la audiencia pública. El acto de defensa consiste en la exposición oral del doctorando del trabajo de investigación realizado, debiendo prestar especial atención, como recoge el Reglamento de Estudios de Doctorado de la UMA en su art. 28.9, a la descripción de la metodología, los contenidos y las conclusiones de la tesis doctoral, con especial mención a las aportaciones originales del trabajo ${ }^{50}$. Aunque no se establece el tiempo que haya de durar la defensa, por lo general, es el propio Presidente del Tribunal quien al iniciar formalmente la sesión y previamente a dar la palabra al doctorando, suele indicar el tiempo de que dispone el doctorando para su defensa $^{51}$. A efectos formales, es adecuado, por parte del doctorando, una vez conferida la palabra, comenzar solicitando "la venia" al Tribunal. Tampoco es inusual dedicar unos minutos, en nuestro caso al final de la defensa, a agradecimientos.

El momento de la defensa es, sin lugar a dudas, el más complicado y difícil de afrontar y con el que, al fin y al cabo, terminas "jugándote" casi a una carta el trabajo de años. En nuestro caso, fue esencial para el éxito de la lectura de la tesis el papel previo del Director de la misma pero, junto a él, también de un grupo de compañeros que gentilmente se ofrecieron para realizar en las semanas previas a la fecha fijada, varias simulaciones del acto. No es infrecuente emplear presentaciones en el acto de lectura, aunque no fue nuestro caso, sin duda, dan cierta tranquilidad. También disponer de un pequeño guión con las cuestiones fundamentales y la estructura de la exposición. Algunas cuestiones esenciales, tranquilidad (lo cual no es nada fácil, pero es cierto que los tres/cuatro primeros minutos son vitales y en ellos los nervios son inevitables, pero a partir de ahí, se empieza realmente a tomar consciencia e, incluso, a disfrutar de ese momento único en la vida), mantener un tono firme y pausado, jugar con los tonos y tratar de evitar el discurso continuo que puede terminar aburriendo al Tribunal, también una adecuada vocalización y enfatizar, incluso jugando con los tonos, en las aportaciones que realiza la investigación ${ }^{52}$.

\footnotetext{
${ }^{49}$ El Reglamento de Estudios de Doctorado de la UMA, establece que sí el día fijado para el acto no se presentará alguno de los miembros titulares, se incorporarán los miembros suplentes del Tribunal. Únicamente si no fuera posible, el presidente habrá de suspender el acto y fijar nueva fecha, comunicándolo a la Comisión de Posgrado. Se prevé incluso en circunstancias excepcionales o de fuerza mayor, y siempre que los medios técnicos lo permitan, y para el caso en que no se presentara alguno de los miembros titulares y ninguno de los suplentes pudiera incorporarse al Tribunal, la posibilidad de que uno de los miembros comparezca mediante conferencia virtual, extremo que deberá recogerse expresamente en el acta.

50 Para el caso de tesis que opten al título de Doctor con Mención Internacional, el Reglamento de Estudios de Doctorado de la UMA establece en au art. 28.9 que, el doctorando deberá efectuar parte de la exposición oral (al menos, la descripción de resultados y conclusiones) en una de las lenguas habituales para la comunicación científica en su campo de conocimiento, distinta a cualquiera de las lenguas oficiales en España. Lo anterior, no será de aplicación cuando las estancias, informes y miembros del Tribunal procedan de un país de habla hispana o así se acuerde por unanimidad por los miembros del Tribunal.

${ }^{51}$ Por lo general, suele oscilar entre los 30 minutos y 1 hora.

${ }^{52}$ En nuestro caso, fue fundamental una idea muy presente desde los días previos y que me acompañó durante el acto de lectura y defensa: mi Director apostó por mi desde el primer momento, me tendió su
} 
Volviendo al plano formal, concluida la exposición oral, el Presidente tomará de nuevo la palabra. De conformidad con el art. 28.11 del Reglamento de Estudios de Doctorando de la UMA, en este momento del acto deberá llevar a cabo “... un resumen oral con los aspectos más relevantes expresados en los informes externos que recibió la tesis, y del informe del doctorando que detalla su respuesta a estos informes. El doctorando podrá responder a los aspectos destacados por el presidente en cuanto a los informes externos y las posibles observaciones".

Tras ello, los miembros del Tribunal deberán expresar su valoración sobre la tesis presentada y podrán formular cuantas cuestiones observaciones, sugerencias y objeciones estimen oportunas. En la práctica, es casi un "ritual" el hecho de que formulen primero alabanzas a la tesis y tras ello vengan las "recomendaciones" e incluso "críticas" a la misma. También está previsto que los doctores presentes en el acto público puedan formular cuestiones en el momento que señale el Presidente del Tribunal. Es el momento en que el doctorado toma nuevamente la palabra para defender y responder a las cuestiones planteadas que, en ocasiones, incluso lo que propiamente plantean es un interés del Tribunal por determinadas cuestiones sobre las que profundizar o dar el parecer.

Finalizado el acto formal, el Tribunal a puerta cerrada pasa a deliberar. Conforme al Reglamento de Estudios de Doctorado de la UMA, en el art. 29, es lo que denomina "valoración de la tesis", en la que cada miembro del Tribunal deberá elaborar un informe razonado de valoración en el que evalúe tanto el trabajo como la exposición y defensa oral realizada por el doctorando, documento que será incorporado al expediente. El Tribunal emitirá un informe y la calificación global concedida a la tesis (no apto, aprobado, notable y sobresaliente), previa votación en sesión secreta, calificación que será recogida en el acta y que habrán de firmar todos los miembros. Tras ello, nuevamente tendrá lugar pública audiencia, en la que el Tribunal comunicará al doctorando, la calificación obtenida de entre las señalas anteriormente.

Cuestión distinta es sí el Tribunal decide otorgar la mención "cum laude" a la tesis doctoral, lo que no se conocerá en el acto sino con posterioridad. Así está previsto expresamente en el Reglamento de Estudios de Doctorado de la UMA, cuyo art. 29.4, recoge tal posibilidad únicamente para el caso de que la calificación global de la tesis doctoral sea sobresaliente, en cuyo caso cada uno de los miembros del Tribunal emitirá su voto secreto, finalizado el acto de defensa, en un sobre que quedará cerrado y firmado en la solapa por todos ellos. Con posterioridad, incluso ese mismo día en función del horario en que haya tenido lugar el acto, el secretario del Tribunal o el miembro del Tribunal que pertenezca a la UMA, será el encargado devolver el expediente de la tesis junto con el sobre a la Comisión de Posgrado. La apertura del sobre y el escrutinio de los votos se realizarán en el momento de la entrega del expediente de defensa de la tesis en el Servicio de Doctorado. Si los tres votos son favorables a la concesión del "cum laude", el doctorando obtendrá la mención "cum laude" lo que se hará constar en el expediente ${ }^{53}$.

mano y su confianza, llevábamos años de trabajo, también momentos de "bajón" en los que paso de ser el maestro al confidente que me empujaba a proseguir. Contaba con un Tribunal de excepción, conformado por prestigiosos colegas suyos y en ese día debía y tenía que estar a la altura de las circunstancias.

${ }^{53}$ La mención "cum laude" a una tesis doctoral es una cuestión que ha abierto diversos debates jurídicos, dando lugar incluso a diferentes resoluciones judiciales. En este sentido, pueden verse entre otras, las Sentencias del Tribunal Superior de Justicia de Galicia, Sala de lo Contencioso, Sede A Coruña, de 17 de enero de 2018 (ECLI: ES:TSJGAL:2018:21); Tribunal Superior de Justicia de Madrid, Sala de lo Contencioso, Sede Madrid, de 05 de diciembre de 2017 (ECLI: ES:TSJM:2017:13350); Tribunal 


\section{Reflexiones.}

A modo de reflexiones, el procedimiento que conlleva la lectura y defensa de una tesis doctoral, con el que concluye los estudios de tercer ciclo, constituyen una encrucijada de trámites procedimentales, cuya superación se instituye en requisito indispensable para poder concurrir al acto formal de defensa ante un Tribunal.

La escueta regulación contenida en el RD 99/2011, marco de referencia en desarrollo de la LOU para las enseñanzas oficiales de doctorado, y la encomienda de su desarrollo, en el ejercicio de la autonomía reconocida a las Universidades, a éstas, lleva en la práctica a que para conocer el marco normativo sea preciso acudir a la normativa dictada por cada una de las Universidades, existiendo en la actualidad tantos marcos normativos como Universidades coexisten en España.

En el presente trabajo se toma como referente la normativa prevista por la Universidad de Málaga contenida en el Reglamento de los Estudios de Doctorado. Ahora bien, como se ha tenido ocasión de analizar, esta regulación es preciso complementarla con las diferentes "guías", instrucciones, formularios e indicaciones que la propia Universidad de Málaga a través de su página web pone a disposición de los doctorados. Si bien se ha podido comprobar el importante trabajo desarrollado en este sentido por las diferentes áreas que tienen un papel relevante en el procedimiento, en ocasiones, la dispersión de la información unida al desconocimiento del doctorando sobre el proceso al que se enfrenta y la multitud de trámites que conlleva, devienen en una etapa compleja en la que no es infrecuente que no se tenga del todo claro (al menos en nuestro caso) todos y cada uno de los trámites que se han de cumplimentar y el momento para ello, así como los diferentes plazos que se suceden.

En este sentido, el objetivo del trabajo, como se indicaba a su comienzo, no es otro que recopilar el conjunto de información disponible que complementa el marco regulatorio previsto por la UMA y aportando, además, la experiencia propia. Todo ello tratando de que el doctorando que, finalizada su tesis doctoral, haya de enfrentarse al mismo, pueda contar con un documento con el que de antemano conozca las cuestiones esenciales del proceso al que se enfrentará en los próximos meses así como los diferentes recursos disponibles. Todo ello, con una única meta: agilizar y facilitar el procedimiento pero a la par, tratando de aportar la experiencia recientemente vivida, de forma que los futuros doctores con la lectura del presente artículo tengan sintetizada la principal información.

\section{Bibliografía.}

-AMOEDO SOUTO, C.A. (2017) "El impacto de las Leyes 39 y 40/2015 en las Universidades públicas: contenido, hipótesis y retos de futuro". Revista Española de Derecho Administrativo, № 182 (enero-marzo): págs. 283-312.

-CAMINO, J.R. (2014) Cómo escribir y publicar una tesis doctoral. Editorial Esic.

-CRIADO SÁNCHEZ, A.J. (2017) Como hacer una tesis doctoral con los planes de Bolonia. Fundación Formación y Desarrollo Urbanístico, $2^{\text {a }}$ edición.

Superior de Justicia de Galicia, Sala de lo Contencioso, Sede A Coruña, de 05 de diciembre de 2017 (ECLI: ES:TSJGAL:2017:7901); o Tribunal Superior de Justicia de Madrid, Sala de lo Contencioso, Sede Madrid, de 23 de octubre de 2017 (ECLI: ES:TSJM:2017:12126). 
-ECO, H. (2014) Cómo se hace una tesis doctoral: técnicas y procedimientos de estudio, investigación y escritura. Vol. 7, Editorial Gedisa.

-HUERGO LORA, A.J. (2016) "Las Leyes 39 y 40/2015. Su ámbito de aplicación y la regulación de los actos administrativos”. El Cronista del Estado Social y Democrático de Derecho, $\mathrm{N}^{\mathrm{o}}$ 63, IUSTEL, (ejemplar dedicado a: Las nuevas leyes de procedimiento administrativo común y régimen jurídico del sector público: págs. 4-13.

-LIÑÁN GARCÍA, A. (2015) "El nuevo Espacio Europeo de Educación Superior: La puesta en valor del profesorado de las Universidades públicas españolas". REIJE, Revista Jurídica de Investigación e Innovación Educativa. Núm. 12: págs. 23-32. Disponible http://www.eumed.net/rev/rejie/12/rejie12.pdf

-LÓPEZ YEPES, J., FERNÁNDEZ BAJÓN, M.T., SÁCHEZ VIGIL, L., MARTÍNEZ MONTALVO, E., HERNÁNDEZ PACHECHO, F., PRAT SEDEÑO, J., SÁNCHEZ, C.M. (2008) "Criterios para la evaluación de tesis doctorales". Revista General de Información y Documentación, Vol.18, № 1: págs. 293-322.

Disponible http://revistas.ucm.es/index.php/RGID/article/view/10159

-QUEVEDO-BLASCO, R. y BUELA-CASAL, G. (2013) "Evaluación de tesis doctorales: propuestas de mejora". Revista Mexicana de Psicología, enero, Vol. 30, Núm. 1: págs. 69-78. Disponible http://www.redalyc.org/html/2430/243033028008/ .

-UBERTONE, F.P. (2011) "Elegir director de tesis'. Academia. Revista sobre enseñanza del Derecho. Buenos Aires, Argentina. Año 9, Núm. 18: págs. 193-206. Disponible http://www.derecho.uba.ar/publicaciones/rev_academia/revistas/18/elegirdirector-de-tesis.pdf

-RUIZ RESA, J.D. (2016) "La formación en investigación: cómo preparar un Plan de Investigación para realizar una tesis doctoral en ciencia jurídica". REIJE, Revista Jurídica de Investigación e Innovación Educativa, Núm. 14, junio 2016: págs. 23-40.

Disponible http://www.eumed.net/rev/rejie/14/rejie14.pdf

-TARDÍO PATO, J.A. (2015) “¿Tiene sentido que las universidades públicas dejen de ser administraciones públicas en las nuevas leyes del sector público y de procedimiento administrativo común? Documentación Administrativa: Nueva Época, $\mathrm{N}^{\circ} 2$.

Disponible

https://revistasonline.inap.es/index.php?journal=DA\&page=article\&op=view\&path $\% 5$ $\mathrm{B} \% 5 \mathrm{D}=10267 \&$ path\%5B $\% 5 \mathrm{D}=10764$

-VALCÁRCEL CASES, M. (2009) "El posgrado en el marco del Espacio Europeo de Educación Superior: el caso español”. La Cuestión Universitaria, Núm. 5 (Ejemplar dedicado a Europa pasa por Bolonia). 